\title{
PERCEPÇÕES DOS CUIDADORES FRENTE A COMPORTAMENTO DE RISCO NA INFÂNCIA: UM RELATO DE EXPERIÊNCIA ${ }^{1}$
}

\author{
DOI: http://doi.org/10.48195/jie2021-072 \\ Jessica Aguiar²; Ana Claudia Pinto da Silva ${ }^{3}$; Marcli Firpo Bittencourt ${ }^{4}$; Regina Gema \\ Santini Costenaro ${ }^{5}$ Josiane Lieberknecht Wathier Abaid $^{6}$
}

\begin{abstract}
RESUMO
Objetivou-se apresentar um relato de experiência sobre a conduta de pais e/ou cuidadores frente a comportamentos de risco na infância, assim como relacionar tais condutas com a importância das funções executivas para o desenvolvimento infantil. Trata-se de um estudo que é um recorte de um projeto de extensão, de cunho transversal qualitativo, realizado de forma virtual com pais e/ou cuidadores por meio de um link criado no google forms. A pesquisa foi composta de dez respostas de pais e/ou cuidadores de crianças de onze a seis anos de idade. Constatou-se que os pais e/ou cuidadores reconhecem condutas que auxiliam o desenvolvimento saudável das funções executivas nos filhos, como a conversação e o desenvolvimento de autonomia. Conclui-se que essas manifestações podem ser reflexos das intervenções virtuais cada vez mais frequentes por meios eletrônicos. Os grupos de educação parental, mesmo que virtuais, podem auxiliar na educação positiva dessas famílias.
\end{abstract}

Palavras-chave: Crianças; Cuidadores parentais; Funções executivas.

\begin{abstract}
The objective was to present an experience report on the behavior of parents and/or caregivers in relation to risk behaviors in childhood, as well as to relate these behaviors with the importance of executive functions for child development. This is a study that is part of an extension project, of a transversal qualitative nature, carried out virtually with parents and/or caregivers through a link created in google forms. The survey consisted of ten responses from parents and/or caregivers of children aged eleven to six years. It was found that parents and/or caregivers recognize behaviors that help in the healthy development of executive functions in their children, such as conversation and the development of autonomy. It is concluded that these manifestations may be reflections of the virtual technologies that are more and more frequent by eletronic means. Parental education groups, even if virtual, can assist in the positive education of these families.
\end{abstract}

Key Words: Kids; Parantal caregivers; Executive functions.

\footnotetext{
${ }^{1}$ Trabalho de Pesquisa e Extensão - UFN. Iniciação Científica - Probex/UFN

${ }^{2}$ Estudante do Curso de Psicologia. Bolsista Probex/UFN Universidade Franciscana - UFN. E-mail: jessica.aguiar@ufn.edu.br

${ }_{3}^{3}$ Psicóloga e Mestranda pela Universidade Federal de Santa Maria, UFSM. E-mail: anaclaudiaps14@ hotmail.com

${ }^{4}$ Psicóloga e Mestre do Mestrado Profissional em Saúde Materno Infantil - UFN. E-mail: m.firpo@ufn.edu.br

${ }^{5}$ Enfermeira. Professora do Curso de Enfermagem, Psicologia e do Mestrado Profissional em Saúde Materno Infantil - UFN. E-mail: regina@ufn.edu.br

${ }^{6}$ Orientadora. Professora do Curso de Psicologia e do Mestrado Profissional em Saúde Materno Infantil - UFN. josianelieb@ufn.edu.br
} 


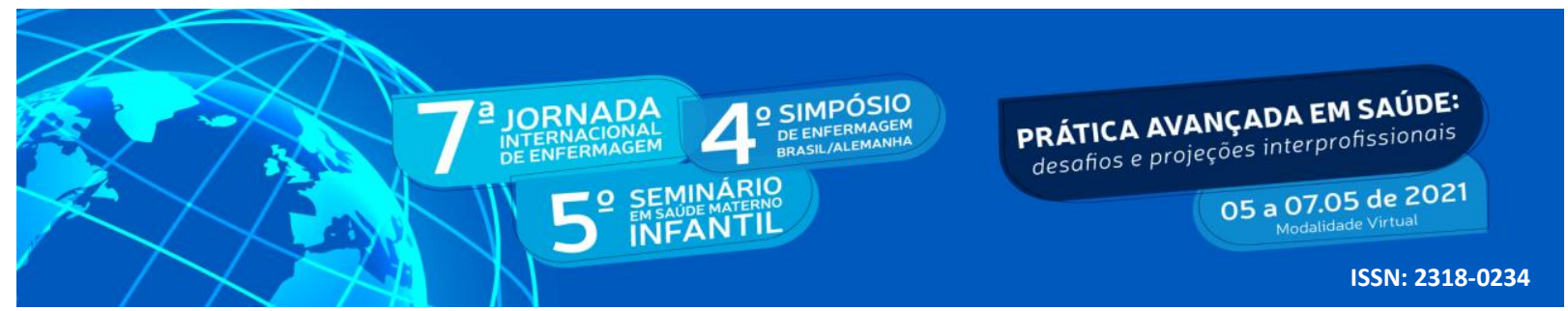

\section{INTRODUÇÃO}

As funções executivas são um conjunto complexo de habilidades que auxiliam o indivíduo no gerenciamento da cognição e do comportamento, permitindo a adaptação a um determinado contexto. Apesar de não haver uma delimitação específica do que são as funções executivas, pode-se salientar que estudos entram em concordância sobre as seguintes funções: controle atencional e inibitório, flexibilidade cognitiva, identificação de metas, iniciação de tarefas, planejamento e execução de comportamentos e autorregulação (CARDOSO; HOLMER, 2018; UEHARA et al., 2016).

O desenvolvimento das funções executivas tem início na infância e continua ao longo da adolescência até a idade adulta. Deste modo, percebe-se, a partir das funções citadas acima, que o seu desenvolvimento tem uma forte influência em aspectos sociais e acadêmicos do indivíduo. Para isso, é importante a presença de um adulto que sirva como modelo e que ensine estas funções à criança, para um desenvolvimento saudável (MARTINS; LEÓN; SEABRA, 2016; UEHARA et al., 2016).

Em vista disso, percebe-se a relevância e a necessidade de os pais e/ou cuidadores disporem de um conhecimento mínimo destas funções e da sua importância para o desenvolvimento dos filhos. Dentre muitos aspectos, os grupos de educação parental podem auxiliar os pais e/ou cuidadores a compreender não somente a existência destas funções e o que são, mas também, como desenvolvê-las em seus filhos (CARDOSO; HOLMER, 2018).

Dessa forma, esse estudo se justifica pelo entendimento da importância de um desenvolvimento saudável das funções executivas no que se refere ao desenvolvimento infantil. As condutas parentais frente ao comportamento dos filhos podem favorecer ou inibir esse desenvolvimento. Assim, é necessário que estes adultos conheçam e pratiquem ações promotoras no dia-a-dia com seus filhos.

\section{OBJETIVO}

O objetivo deste trabalho consistiu em apresentar um relato de experiência sobre a conduta de pais e/ou cuidadores frente a comportamentos de risco na infância, assim como 


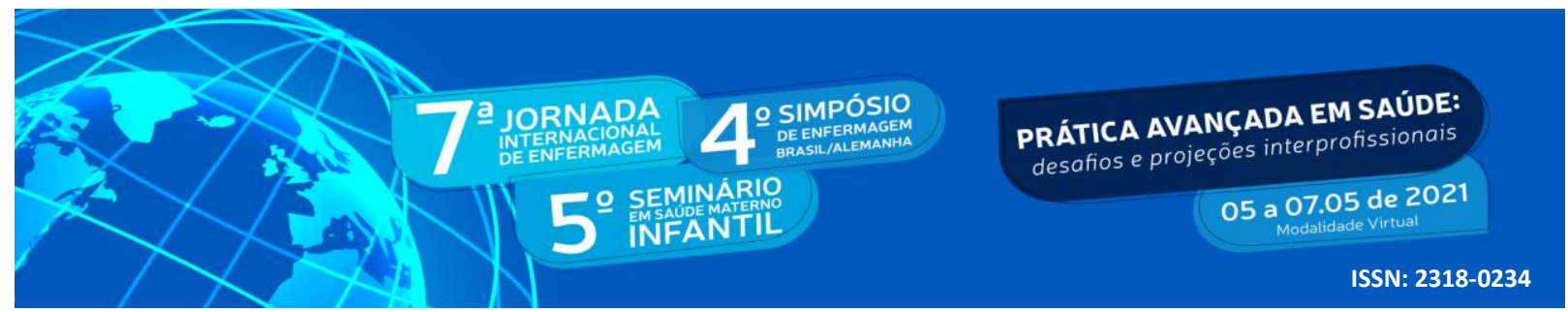

relacionar tais condutas com aportes teóricos sobre a importância das funções executivas para o desenvolvimento infantil.

\section{METODOLOGIA}

Este trabalho trata-se de um relato de experiência, que aponta alguns recortes de um projeto de extensão do curso de Psicologia de uma instituição de ensino superior situada no interior do Rio Grande do Sul. Tal projeto é intitulado "Educação parental em tempos pandêmicos: Promoção das relações familiares positivas com intervenção on-line" (ABAID; COSTENARO, 2020), o mesmo foi aprovado pelo Comitê de Ética em Pesquisa com Seres Humanos sob o registro do CAAE: 08975619.6.0000.5306, $\mathrm{n}^{\circ} 4.489 .573$, no ano de 2021.

Dessa forma, o estudo se caracteriza por meio de uma pesquisa de cunho transversal qualitativo. A mesma é realizada de forma observacional com carácter transversal mediante a análise de dados qualitativos coletados ao longo de um determinado período de tempo. São coletados dados de uma população amostral ou de um subconjunto predefinido que possuem características em comum (GIL, 2008), por exemplo, pais e/ou cuidadores que possuem filhos em idade infantil. Em outras palavras, esse tipo de estudo capta as opiniões de um grupo de pessoas em um momento específico.

A pesquisa foi realizada com pais e/ou cuidadores via google forms mediante o envio de um link eletrônico, com 4 perguntas para serem respondidas. A primeira refere-se ao acesso dos pais e/ou cuidadores no instagram do "Projeto Pais Mais". Na sequência foram apresentadas algumas imagens: a primeira sobre um caso de uma criança de cinco anos que estava com fome e decidiu subir um banquinho para alcançar o pote de bolachas no armário aéreo. Logo após, foram apresentadas imagens com explicações teóricas sobre a importância das funções executivas, conforme o instagram do projeto (@ projetopaismaisufn).Em seguida foi solicitado que os pais e/ou cuidadores relatassem uma situação semelhante ao caso do menino de cinco anos e como eles reagiram frente a este acontecido, assim como a idade da criança nesse período e o quais conteúdos gostariam de visualizar no instagram do projeto. E por fim, os achados foram relacionados com estudos de cunho nacional e internacional publicados nos últimos cinco anos. 


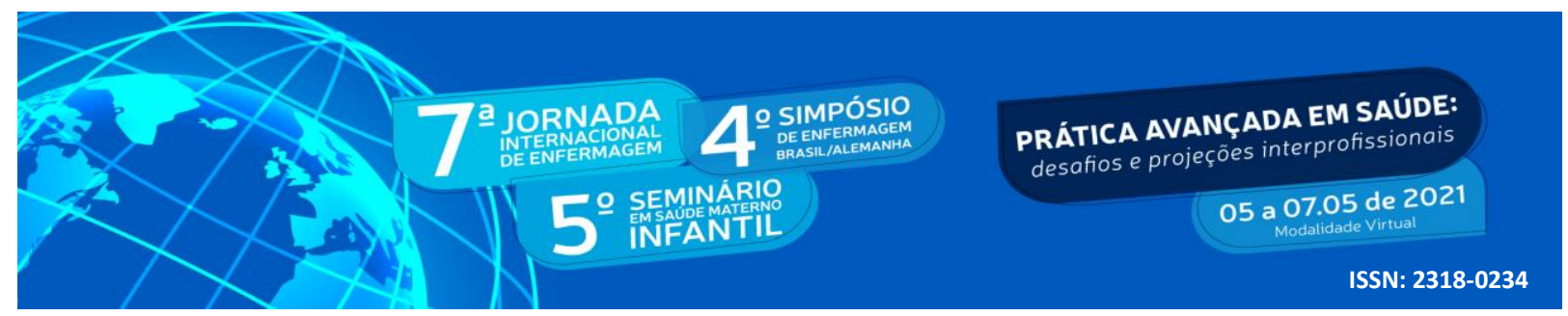

\section{RESULTADOS E DISCUSSÃO}

Por meio da pesquisa realizada de forma on-line, foram obtidas 13 respostas, sendo que uma estava repetida e dois cuidadores não descreveram nenhum tipo de comportamento de risco em seus filhos. Assim, a pesquisa foi composta por dez respostas. A idade das crianças variou de onze meses a 6 anos de idade. Dessa forma, os participantes serão apresentados pela letra (P) e com o respectivo número conforme responderam as perguntas no google forms.

Nesse sentido, foi apresentado via imagem aos pais e/ou cuidadores um pequeno caso de uma criança de cinco anos produzindo um comportamento de risco para si mesmo e as reações de sua mãe (Figura 1). Esta situação exemplo serviu como um disparador para os pais/ou cuidadores recordarem acontecimentos, nas quais seus filhos também se colocaram em risco e como elas/eles reagiram frente a estes comportamentos.

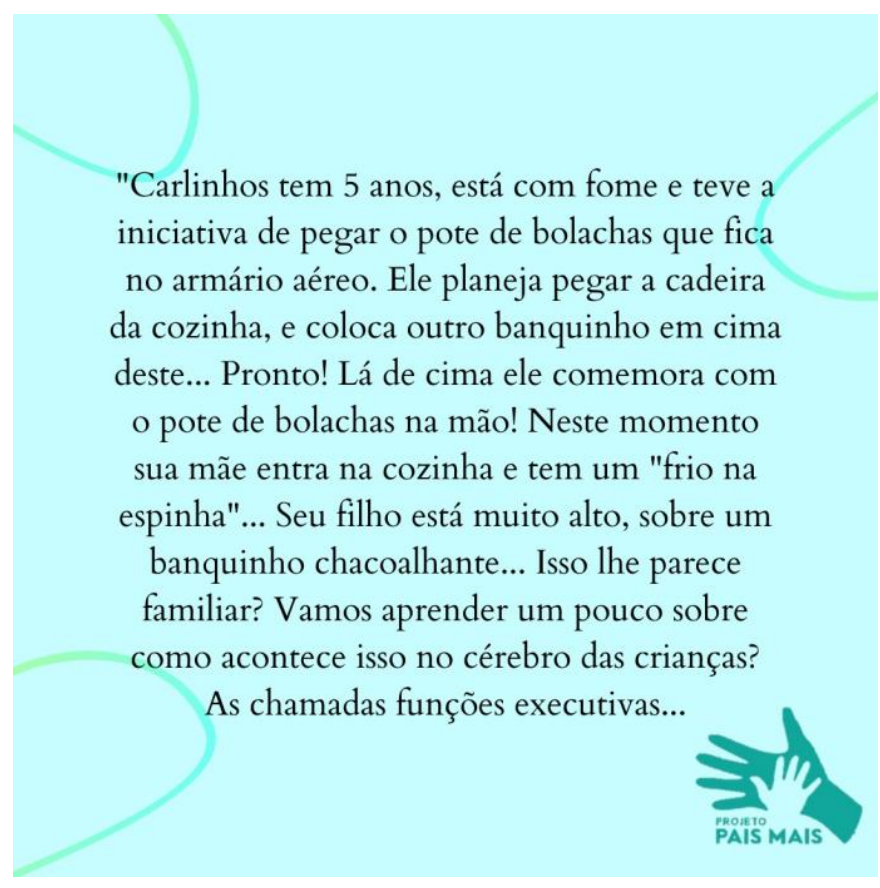

Figura 1: Post do Instagram Pais Mais.

Fonte: Elaborada pelas autoras, 2021.

Partindo das respostas descritas pelos pais e/ou cuidadores, o participante (P1) trouxe que o filho "estava ajudando a lavar os talheres e se cortou com a faca" enquanto o 


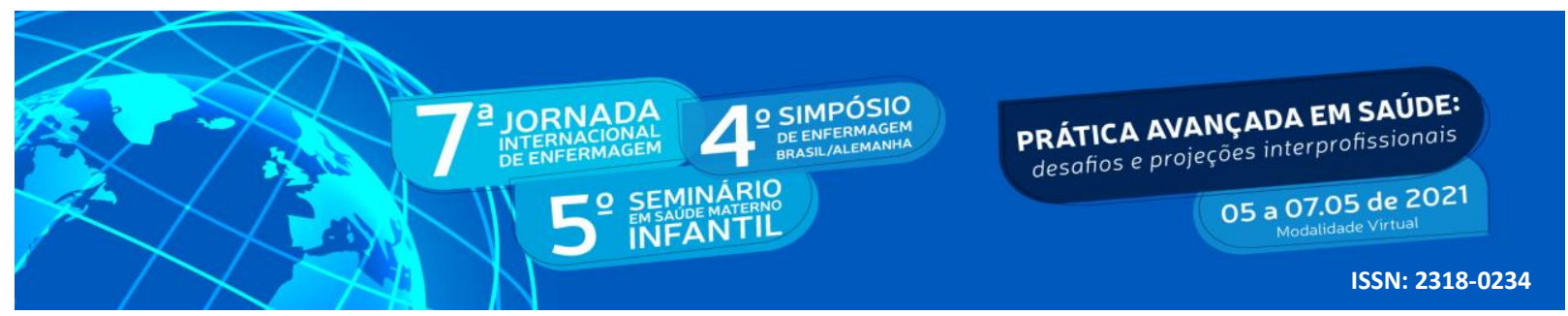

participante (P4) disse que: "a minha filha quando sentia sono, ia até o berço sozinha escalava para deitar e dormir. Ainda bem que eu sempre estava por perto e nunca aconteceu dela cair."

A promoção de autonomia é um fator que está intrinsecamente relacionado às funções executivas, visto que esta proporciona a exploração do ambiente em que a criança se encontra inserida. Os pais e/ou cuidadores são os principais responsáveis pela promoção deste aspecto, ao permitir que seus filhos realizem tarefas de forma independente, mas com a sua presença caso seja necessário o auxílio no decorrer do percurso (REICHENBACH; BASTIAN; ROHRBACH; GROSS; SARRAR, 2017). Em vista disso, a construção da autonomia desde a infância é muito importante para a criança, pois auxilia na criação do sentimento de autoeficácia e consequentemente na sua autoestima (NPCI, 2016).

Os participantes P2, P5 e P10 trouxeram a conversação como forma de reagir aos comportamentos de risco dos filhos, percebidos pelas falas a seguir:

Ela pegou um recipiente colocou leite e com a colher ao lado (de metal) se preparava para aquecer no microondas quando eu entrei na cozinha, eu ao ver me assustei pois não sabia se a colher não iria junto, parei e expliquei que ela poderia me chamar que eu aqueceria para ela, mas caso fosse aquecer só poderia colocar material de plástico pois outro material não pode e expliquei o porquê (P2).

Nesse mesmo sentido, o participante P5 descreveu:

Meu filho subiu em um baú de brinquedos para pegar os bonecos na prateleira. Mas o baú tem rodinha. Quando vi, expliquei que poderia cair e se machucar e que não era indicado subir no baú e sim chamar a mãe, o pai e a mana para pegar os bonecos.

Já o participante P10 aponta em sua escrita que:

Minha filha de cinco anos pegou sua irmã bebê do berço e veio até a mim que estava na cozinha preparando algo e ela estava com sua irmã bebê de cabeça para baixo daí me deu um frio na espinha e respirei com calma pegando o bebê e me abaixando falei devagarinho com a irmã mais velha.

Para além da autonomia, a construção de um espaço de diálogo é essencial para o desenvolvimento da criança e também auxilia nas funções executivas, no momento em que possibilita o entendimento de regras e da adequação de determinados comportamentos. Sendo assim, é muito importante que os pais e/ou cuidadores expliquem para a criança o motivo de determinado comportamento não ser adequado, evitando a adoção de medidas punitivas. Esta atitude permite que a criança se sinta acolhida e com o passar do tempo internalize a adequação ou risco de certos comportamentos e solicite o auxílio do adulto quando necessário (CARDOSO; HOLMER, 2018; CARVALHO, 2017; NPCI, 2016). 


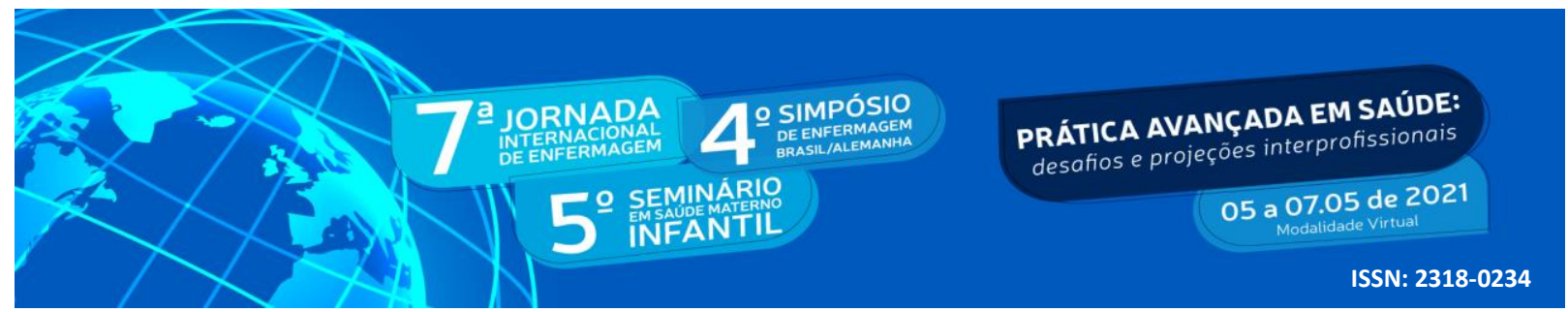

A percepção da imaturidade do filho foi descrita por cuidadores de crianças de até 2 anos, visto que estes ainda não possuem controle inibitório e entendimento do que pode ou não ser perigoso. O participante P3 apresentou que: "meu filho enfiou uma chave na tomada. $\mathrm{Na}$ hora me assustei dei um grito ele soltou rapidamente disse não que machucava”. O participante P9 vivenciou uma situação parecida: "em questão de segundos que virei as costas encontrei meu filho tentando colocar o dedo na tomada, na hora paralisei, logo gritei com ele para não fazer isso porém ele me ignorou, então corri até ele é evitei o pior. ” Já o participante P6 contou que quando: "cheguei no quarto dele e ele havia tirado todas as roupas da última gaveta do armário dele. Ele não tinha me visto ainda, então comecei a gravar a "arte" dele.

Como descrito anteriormente, as funções executivas são desenvolvidas da infância até a idade adulta. Sendo assim, em crianças muito pequenas algumas funções, como o controle inibitório, ainda não estão bem desenvolvidas (SANTA-CRUZ; ROSAS, 2017). Por isso, as crianças que se encontram na primeira infância costumam ter dificuldade de compreender e obedecer ordens, assim como, parar e pensar antes de agir, o que gera comportamentos impulsivos (CRESPI; NORO; NÓBILE, 2020).

Consequentemente, é importante que os cuidadores compreendam que isso se trata de uma fase do desenvolvimento cerebral e que alguns comportamentos de risco ocorrem na tentativa da criança explorar o ambiente ao seu redor. Manter uma relação positiva com os filhos para ajudá-lo a se preparar melhor para lidar com situações estressantes e desconhecidas , sendo afetuoso e sensivel às necessiddaes deles, ajudará a desenvolver suas funções executivas.Dessa forma, é fundamental que a criança seja supervisionada por um adulto sempre que possível, para evitar que ocorram acidentes (CARDOSO; HOLMER, 2018; NPCI, 2016).

$\mathrm{O}$ participante $\mathrm{P} 7$ trouxe em sua fala aspectos que remetem tanto à promoção de autonomia como descrito acima, como a iniciação de tarefas e autogerenciamento, como se pode ler em: "ela geralmente pega cadeiras e sobe para usar a pia quer ajudar na cozinha mas o medo que temos que caíam é constante mas mantenho a calma e deixo pois tem que se virar sozinha."

Algumas crianças costumam imitar comportamentos da rotina dos cuidadores, visto que eles são seus principais modelos de conduta. A inclusão das crianças em tarefas adequadas a sua idade é fundamental para o desenvolvimento de questões como o planejamento, iniciação 


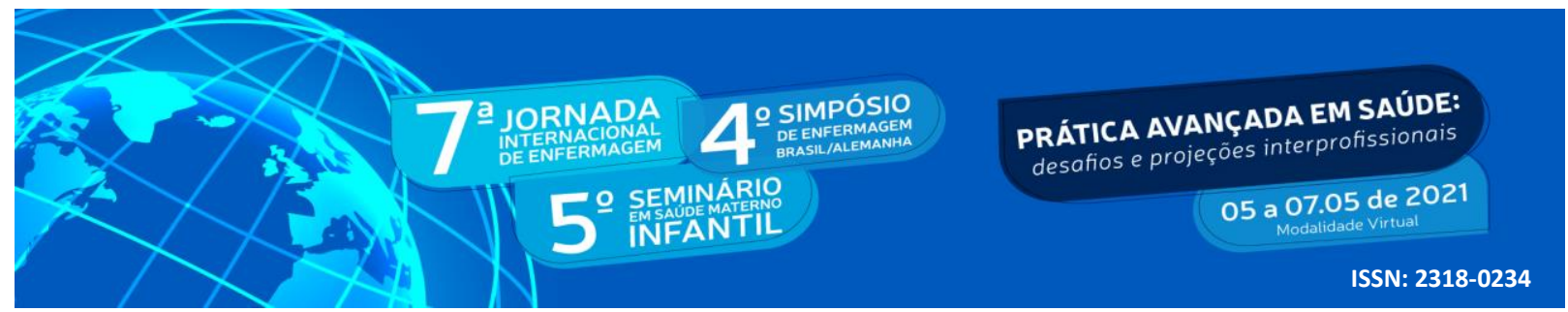

de tarefas, rotina e autogerenciamento, atividades que fazem parte das funções executivas. Sendo que essas, são de extrema importância para a aquisição de limites fundamentais, internalização da educação e execução de atividades no âmbito acadêmico e social ao longo de toda a vida da criança (BARRASSO-CATANZARO; ESLINGER, 2016; CARDOSO; HOLMER, 2018).

A flexibilidade cognitiva foi percebida na fala da participante P8, visto a adaptação da filha a uma situação nova:

Na pandemia, só podemos sair de máscara. Várias vezes minha filha me lembrou que eu estava sem e a gente precisava voltar pra buscar. Fiquei orgulhosa e tranquila por saber que ela pode se adaptar a situações de cuidado com a própria vida e a dos outros.

A flexibilidade cognitiva se refere à capacidade da criança se adaptar ao meio em que está inserida, em resposta a mudanças ou desafios percebidos. Mesmo sem perceber, os cuidadores acabam tendo influência no desenvolvimento deste aspecto, ao possibilitar que seus filhos compreendam que nem tudo sai como planejado e que novas estratégias podem ser adotadas (CARDOSO; HOLMER, 2018; CRESPI; NORO; NÓBILE, 2020). Manter uma relação positiva com os filhos para ajudá-los a se preparar melhor para lidar com situações estressantes e desconhecidas, sendo afetuoso e sensivel às necessiddaes deles, ajudará a desenvolver suas funções executivas.

Compreende-se assim, que as funções executivas têm um papel essencial no desenvolvimento do indivíduo. Podendo ser promovidas através de atividades cotidianas que fazem parte da rotina da criança e tendo influência no seu desempenho acadêmico e social. Com relação a isso, a maneira que os pais e/ou cuidadores promovem a educação parental dos seus filhos, tem influência significativa na formulação saudável ou não das funções executivas. Dessa forma, fica perceptível a relevância de grupos que promovam a consciência de uma educação parental positiva, no intuito de proporcionar técnicas de manejo que auxiliem os pais e/ou cuidadores a compreender as demandas dos filhos.

\section{CONCLUSÃO}

Percebe-se assim, que grande parte dos cuidadores que participaram deste estudo relataram condutas que influenciam um desenvolvimento saudável das funções executivas dos 


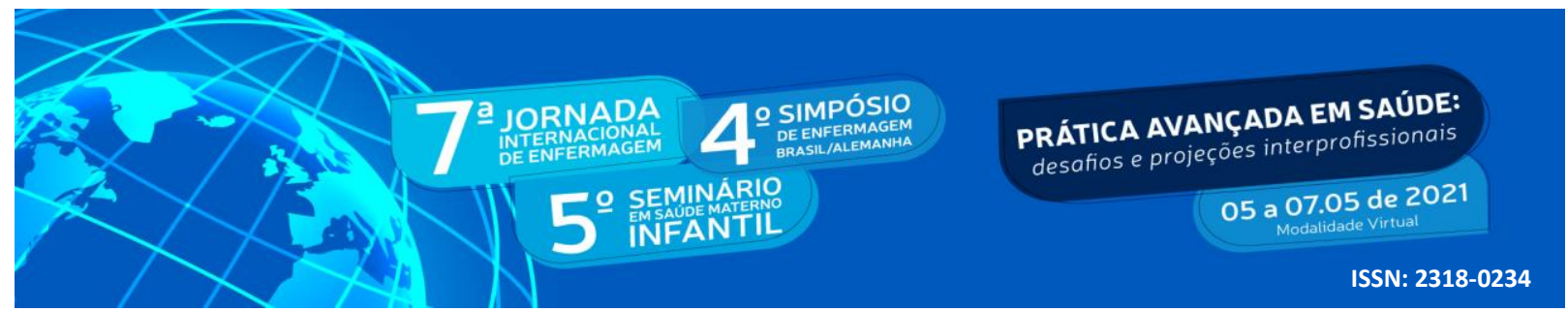

filhos. Através de aspectos como a conversação, promoção da autonomia, compreensão da imaturidade do filho, incentivo a iniciação de tarefas, autogerenciamento e autorregulação e flexibilidade cognitiva.

Traz-se como limitações, o fato do número estudado ser restrito. O que consequentemente impossibilita a generalização dos resultados aqui expostos para outros contextos. Um fator a ser destacado é que $84,6 \%$ dos cuidadores que responderam ao formulário não tinham tido acesso a página do Instagram, enquanto somente 15,4\% já haviam acessado a página. Esses dados reforçam a concepção de que ainda são poucos os cuidadores que possuem tal rede social, sendo que a maior parte do nosso público na página do Instagram são da área acadêmica.

Ademais, os cuidadores que responderam ao formulários ressaltaram o interesse em relação a produção de conteúdos pela página do Instagram sobre temas como: regulação emocional dos cuidadores e das crianças, orientações de como manejar o mal comportamento, sugestões de brincadeiras criativas envolvendo os familiares na pandemia e aspectos da saúde mental do grupo familiar.

\section{REFERÊNCIAS}

ABAID, J. L. W.; COSTENARO, R. G. S. Projeto de extensão "Educação parental em tempos pandêmicos: promoção das relações familiares positivas com intervenção on line". Edital n. 15/2020 (PROBIC/PROBEX/PROBIT). Universidade Franciscana, Pró-Reitoria de Pesquisa e Relações Comunitárias, 2020.

BARRASSO-CATANZARO, C.; ESLINGER, P. J. Neurobiological bases of executive function and social-emotional development: typical and atypical brain changes. Family Relations, v. 65, p. 108-119, 2016.

CARDOSO, C. O.; HOLMER, L. Responsabilidades: orientações sobre funções executivas. In: FAVA, D. C.; ROSA, M.; OLIVA, A. D. Orientação para pais: o que é preciso saber para cuidar dos filhos. Novo Hamburgo: Sinopsys, 2018. p. 151-168.

CARVALHO, J. K. M. A relação entre o nível socioeconômico e o desempenho das funções executivas na infância: uma metanálise. 2017. Trabalho de Conclusão de Curso (Bacharelado 


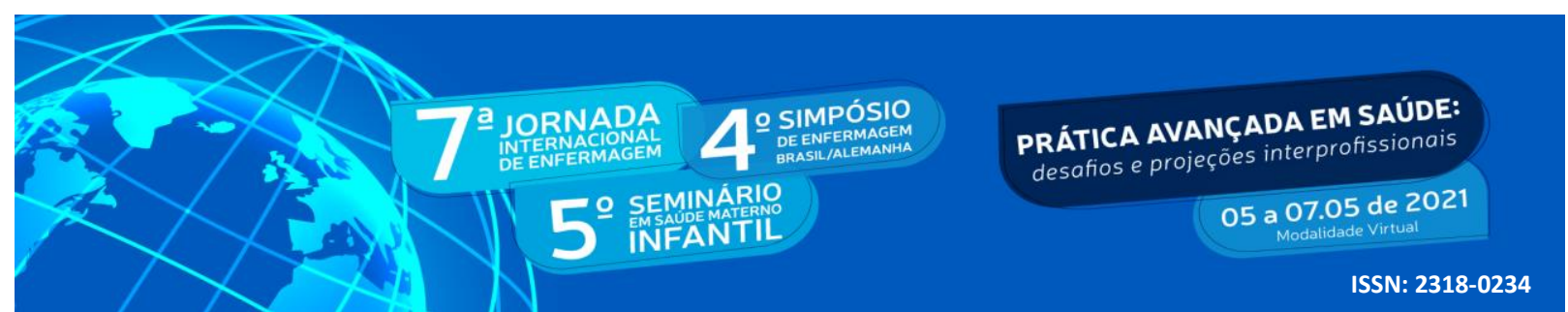

em Psicopedagogia) - Centro de Educação da Universidade Federal da Paraíba, João Pessoa, 2017.

CRESPI, L.; NORO, D.; NÓBILE, M. F. As potencialidades do brincar para o desenvolvimento das funções executivas na primeira infância. Debates em Educação, Maceió, v. 12, n.28, p. 158-177, 2020.

GIL, A. C. Como elaborar projetos de pesquisa. 5. ed. São Paulo: Atlas, 2008.

MARTINS, G. L. L.; LEÓN, C. B. R.; SEABRA, A. G. Estilos parentais e desenvolvimento das funções executivas: estudo com crianças de 3 a 6 anos. Psico, Porto Alegre, v. 47, n. 3, p. 216-227, 2016.

NCPI. Comitê Científico do Núcleo Ciência pela Primeira Infância. Funções executivas e desenvolvimento infantil na Primeira Infância: habilidades necessárias para a autonomia. Estudo nº III, 2016.

REICHENBACH, K.; BASTIAN, L.; ROHRBACH, S.; GROSS, M.; SARRAR, L. Cognitive functions in preschool children with specific language impairment. International Journal of Pediatric Otorhinolaryngology, v.86, p. 22-26, 2016.

SANTA-CRUZ, C.; ROSAS, R. Mapping of executive functions/Cartografía de las funciones ejecutivas. Estudios de Psicología, v.38, n.2, p.284-310. 2017.

UEHARA et al. Funções executivas na infância. In: SALLES, J. F.; HAASE, V. G.; MALLOYDINIZ, L. F. Neuropsicologia do desenvolvimento:infância e adolescência. Porto Alegre: Artmed, 2016. p. 17-27. 